\title{
Staged Nasal Reconstruction Using a Forehead Flap and Rib Bone and Cartilage Graft in a Binder Syndrome Patient: A Case Report
}

\author{
Jae-Woo Heo, Ung Sik Jin \\ Department of Plastic and Reconstructive \\ Surgery, Seoul National University \\ Hospital, Seoul National University \\ College of Medicine, Seoul, Korea
}

No potential conflict of interest relevant to this article was reported.
Binder syndrome is a rare maxillofacial abnormality. Yet, once presented, it often needs to be addressed surgically. To suit this purpose, various surgical techniques have been developed. This paper is a case report of a staged nasal reconstruction in a Binder syndrome patient using rib bone and cartilage graft and forehead flap. At the same time, preoperative and postoperative anthropomorphometric measurements were compared to assess the efficiency of the proposed surgical technique.

Keywords Maxillofacial abnormalities, Nose, Ribs

\section{INTRODUCTION}

First described by von Binder [1] in 1962, Binder syndrome, also known as maxillonasal dysplasia, remains a clinical challenge without a definitive surgical solution. Of unknown etiology, this disorder is easily recognizable by its characteristic appearance, involving a hypoplastic midface that includes a flattened nose, absent anterior nasal spine, convex upper lip, crescent-shaped nostrils, and even bony and dental abnormalities [2]. Various surgical techniques have been proposed, although no gold-standard treatment modality has yet been established. Conventional techniques include the use of alloplastic implants or autologous cartilage grafting for a basic framework, and soft tissue reconstruction for outer contouring [3]. These procedures are usually done in stages [4].

In this paper, we evaluate the preoperative and postoperative anthropometric measurements of a patient with Binder syndrome

Received: Apr 9, 2018 Revised: May 10, 2018 Accepted: May 19, 2018 Correspondence: Ung Sik Jin Department of Plastic and Reconstructive Surgery, Seoul National University Hospital, Seoul National University College of Medicine, 101 Daehak-ro, Jongno-gu, Seoul 03080, Korea. E-mail: usj1011@snu.ac.kr

Copyright () 2018 The Korean Society for Aesthetic Plastic Surgery.

This is an Open Access article distributed under the terms of the Creative Commons Attribution Non-Commercial License (http://creativecommons.org/licenses/by-nc/4.0/) which permits unrestricted non-commercial use, distribution, and reproduction in any medium, provided the original work is properly cited. www.e-aaps.org who underwent staged nasal reconstruction using a rib bone and cartilage graft and a forehead flap.

\section{CASE REPORT}

A 19-year-old female patient visited our institution with the chief complaint of a nasal deformity. She had no history of nasal trauma, and her mid-face profile was hypoplastic. She exhibited the typical features of Binder syndrome: a flattened nasal dorsum with a short septum, a convex upper lip, crescent-shaped nostrils, a short columella $(\mathrm{Cl})$, and a broad philtrum. Radiographic examinations revealed agenesis of the anterior nasal spine with nasomaxillary hypoplasia. No other structural abnormalities were noted.

A staged nasal reconstruction was planned. The first operation was done under general anesthesia. An incision was made along the nasal dorsum and undermining was done from the glabella (Gl) to the nasal tip and bilateral alar (Al) bases to create a subperiosteal pocket. The right fifth rib bone and cartilage were harvested via an inframammary incision. The harvested graft was carved in the shape of the nasal framework (Fig. 1). A left paramedian forehead flap, with supratrochlear vessels as a vascular pedicle, was elevated (Fig. 2). After fixation of grafted bone and cartilage inside the pocket, the elevated flap was rotated to cover the defect on the nasal dorsum (Fig. 3). All wounds were closed by layers. Three weeks later, division of the forehead flap was performed under local anesthesia. Intact perfusion was identified after disconnecting the vas- 
cular pedicle. All procedures were uneventful, without any need for surgical revisions.
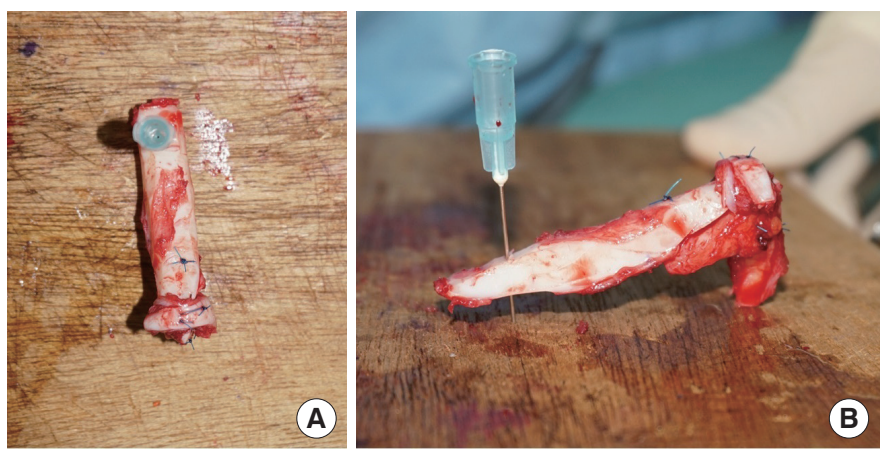

Fig. 1. Nasal framework made using an autologous rib bone and cartilage graft. Apical view (A) and lateral view (B).

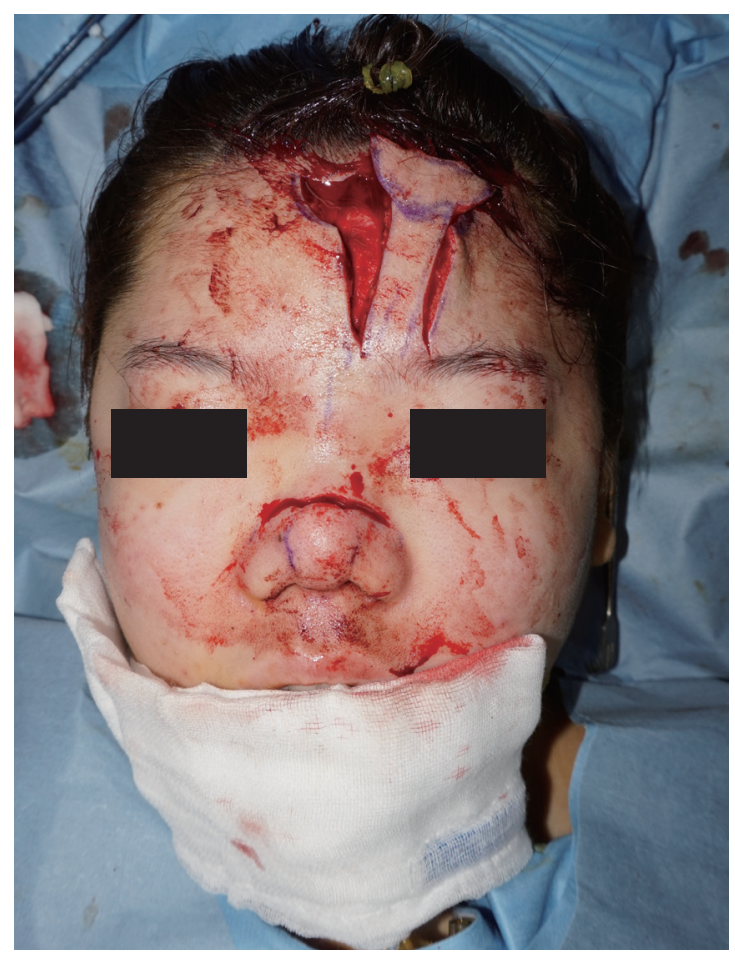

Fig. 2. Paramedian forehead flap after elevation.
The patient's short nose features were successfully corrected and remained stable 1 year after the operation (Fig. 4). The grafted bone and cartilage were well maintained without any signs of selfabsorption. In general, the patient was satisfied with the outcome.

An attempt to evaluate the outcome more objectively was made. The anthropometric measurements described by Farkas and Munro [5] were adopted in this study to compare the patient's preoperative and postoperative facial proportions. The postoperative measurements were recorded 1 year after the last operation. The standard points for measurements in the lateral view were as follows: Gl, nasion $(\mathrm{N})$, pronasale (Prn), sub-nasale (Sn), $\mathrm{Al}, \mathrm{Cl}$, labiale superius (Ls), and pogonion $(\mathrm{Pg})[6]$. Table 1 summarizes the preoperative and postoperative anthropometric measurements of the patient. The nasolabial angle (Cl-Sn-Ls) was $127.0^{\circ}$ preoperatively, and it decreased to $86.6^{\circ}$ at 1 year after the operation. The angle of

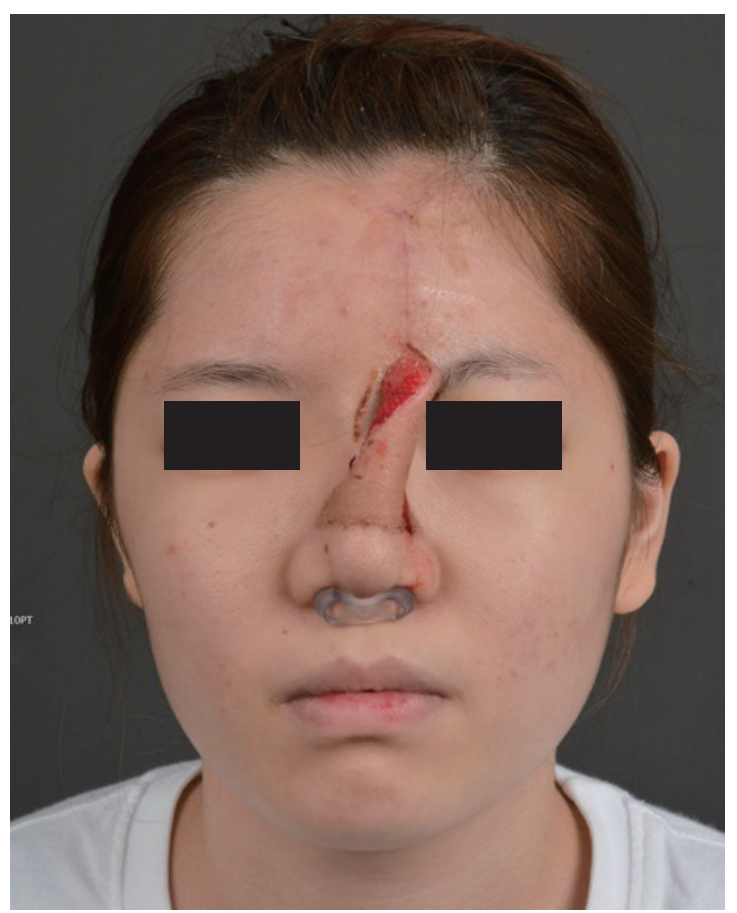

Fig. 3. Immediate postoperative view of the forehead flap and the rib bone and cartilage graft.

Table 1. Preoperative and postoperative anthropometric measurements

\begin{tabular}{|c|c|c|}
\hline & Preoperative $\left({ }^{\circ}\right)$ & Postoperative $\left({ }^{\circ}\right)$ \\
\hline Nasolabial angle (Cl-Sn-Ls) & 127.0 & 86.6 \\
\hline Angle of convexity with the nose from the glabella (Gl-Prn-Pg) & 163.2 & 149.1 \\
\hline Angle of convexity without the nose from the glabella (Gl-Sn-Pg) & 179.6 & 179.3 \\
\hline Angle of convexity with the nose from the nasion (N-Prn-Pg) & 143.1 & 136.1 \\
\hline Angle of convexity without the nose from the nasion (N-Sn-Pg) & 171.3 & 174.9 \\
\hline
\end{tabular}

The points selected for anthropometric measurements in the lateral view were the Gl, N, Prn, Sn, Al, Cl, Ls, and Pg.

GI, glabella; N, nasion; Prn, pronasale; Sn, sub-nasale; Al, alar; Cl, columella; Ls, labiale superius; Pg, pogonion. 

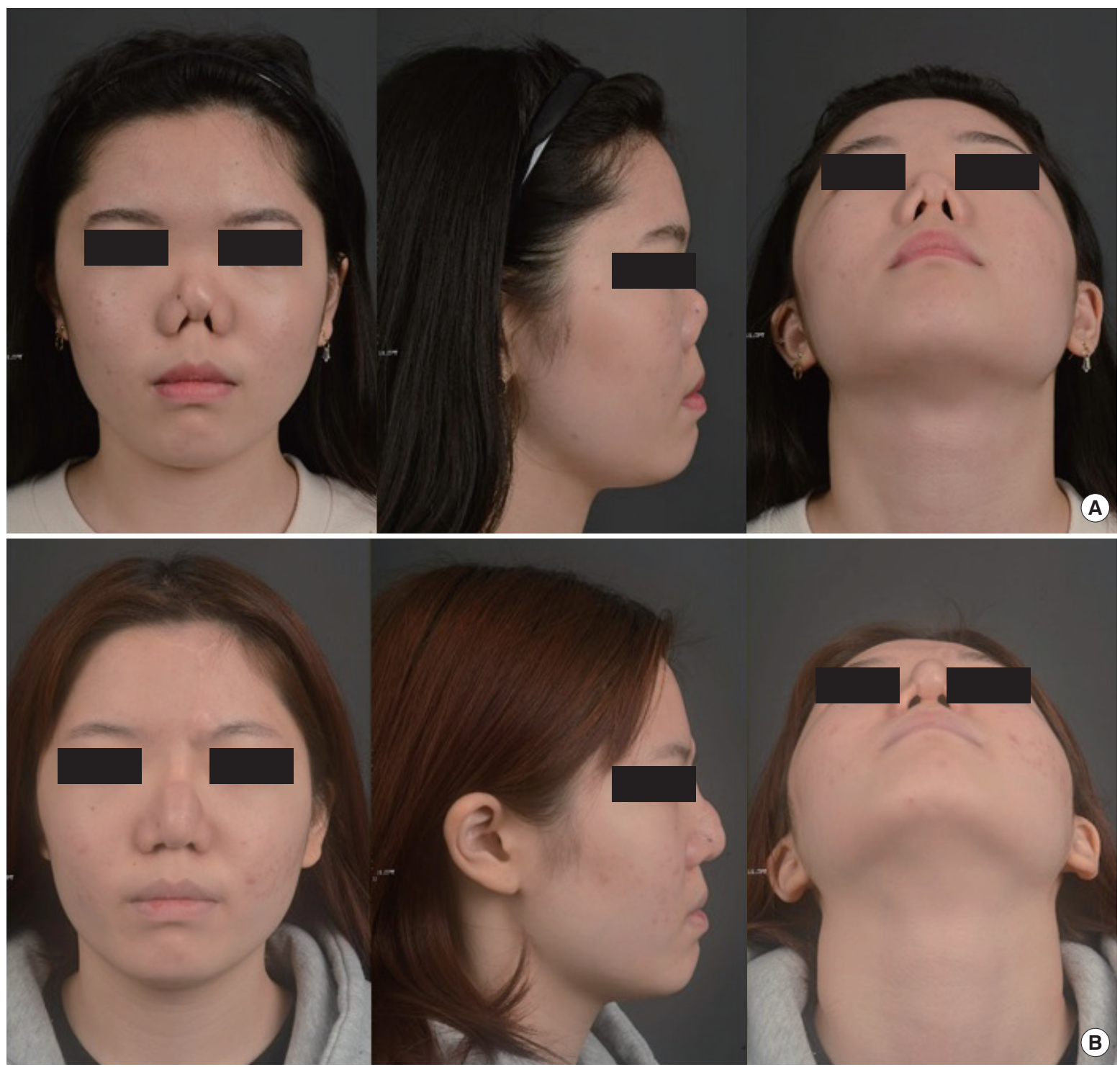

Fig. 4. Preoperative (A) and 1-year postoperative (B) view of the patient in 3 different projections.

convexity from the Gl with the nose (Gl-Prn-Pg) was $163.2^{\circ}$ preoperatively and $149.1^{\circ}$ postoperatively, and the corresponding angle without the nose (Gl-Sn-Pg) was $179.6^{\circ}$ preoperatively and $179.3^{\circ}$ postoperatively. The angle of convexity except nose from the $\mathrm{N}(\mathrm{N}-$ Prn-Pg) was $143.1^{\circ}$ before the operation, but it decreased to $136.1^{\circ}$ postoperatively. The angle of convexity without the nose from the $\mathrm{N}\left(\mathrm{N}-\mathrm{Sn}-\mathrm{Pg}\right.$ ) was $171.3^{\circ}$ and $174.9^{\circ}$ before and after the operation, respectively.

\section{DISCUSSION}

Over the last few decades, surgical techniques for the treatment of Binder syndrome have evolved significantly. However, no method has been decisively identified as the gold standard. In this case re- port, we present a case of staged nasal reconstruction in a patient with Binder syndrome. Previously, various techniques have been devised in an attempt to correct the characteristic features of Binder syndrome, and the forehead flap and rib bone and cartilage graft used in this case proved to be satisfactory.

Autologous bone and cartilage grafts and local flaps are no longer innovative techniques. The combination of these techniques has been frequently used to correct the nasal deformity in Binder syndrome [3]. Furthermore, anthropometric analysis using a digitalized photograph is a widely accepted tool for evaluating a patient's facial profile, as it is reliable and reproducible $[7,8]$. For instance, in 2008, Gewalli et al. [9] used this profile to compare bone versus cartilage grafting for nasomaxillary reconstruction in Binder syndrome patients. 
The preoperative and postoperative angles measured in this study proved the surgical techniques to be efficient. The angle of convexity without the nose from the Gl (Gl-Sn-Pg) represents the facial convexity from the base of the nose and it signifies the level of success of pre-nasal grafting [10]. As the value remained consistent after surgery, we can conclude that the grafting was well taken. The angle of convexity with the nose from the Gl (Gl-Prn-Pg) represents the degree of tip advancement [10]. This angle markedly decreased after the operation and remained stable for at least 1 year postoperatively. As tip projection was an important parameter to assess the surgical outcome, we included this measurement in the study. Meanwhile, the angle of convexity was also measured from the $\mathrm{N}$. While there was an insignificant change in the location of the Gl after the operation, the location of the $\mathrm{N}$ changed dramatically. In this sense, it was worthwhile to measure the angles separately from the $\mathrm{N}$, as well as from the Gl. The change in the angle of convexity from the $\mathrm{N}$ with the nose (N-Prn-Pg) and without the nose (N-Sn-Pg) represent the level of success of grafting and tip advancement, respectively. Finally, the nasolabial angle, which decreased from $127^{\circ}$ to $87^{\circ}$, also showed a notable improvement. The nasolabial angle has long been accepted as an aesthetic parameter for the nasal profile [11].

Taking into account the rare incidence of Binder syndrome, no previous studies have attempted to compare the preoperative and postoperative anthropometric measurements of Binder syndrome patients who underwent a staged nasal reconstruction using a rib bone graft and forehead flap. In this sense, this case report has some degree of significance, as it provides directions for future studies.

\section{PATIENT CONSENT}

Patient provided written consent for the use of her images.

\section{REFERENCES}

1. von Binder KH. Dysostosis maxillo-nasalis, ein arhinencephaler Missbildungskomplex. Dtsch Zahnarzt Z 1962;17:438-44.

2. Noyes FB. Case report. Angle Orthod 1939;9:160-5.

3. Menick FJ. A 10-year experience in nasal reconstruction with the threestage forehead flap. Plast Reconstr Surg 2002;109:1839-55; discussion 56-61.

4. Nedev PK. The Binder syndrome: review of the literature and case report. Int J Pediatr Otorhinolaryngol 2008;72:1573-6.

5. Farkas LG, Munro IR, editors. Anthropometric facial proportions in medicine. Springfield, IL: Charles C. Thomas; 1987.

6. Farkas LG, editor. Anthropometry of the head and face. 2nd ed. New York, NY: Raven Press; 1994.

7. El-Hakim H, Crysdale WS, Abdollel M, et al. A study of anthropometric measures before and after external septoplasty in children: a preliminary study. Arch Otolaryngol Head Neck Surg 2001;127:1362-6.

8. Kohout MP, Aljaro LM, Farkas LG, et al. Photogrammetric comparison of two methods for synchronous repair of bilateral cleft lip and nasal deformity. Plast Reconstr Surg 1998;102:1339-49.

9. Gewalli F, Berlanga F, Monasterio FO, et al. Nasomaxillary reconstruction in Binder syndrome: bone versus cartilage grafts. A long-term intercenter comparison between Sweden and Mexico. J Craniofac Surg 2008;19:1225-36.

10. Monasterio FO, Molina F, McClintock JS. Nasal correction in Binder's syndrome: the evolution of a treatment plan. Aesthetic Plast Surg 1997; 21:299-308.

11. Harris R, Nagarkar P, Amirlak B. Varied definitions of nasolabial angle: Searching for consensus among rhinoplasty surgeons and an algorithm for selecting the ideal method. Plast Reconstr Surg Glob Open 2016;4:e752. 